\title{
The olive tree-ring problematic dating
}

\section{Paolo Cherubini ${ }^{1} \&$ Simcha Lev-Yadun ${ }^{2}$}

We are glad to see that our paper has stimulated a lively debate, and we acknowledge the appreciation of our work by Bietak, Kuniholm and MacGillivray as well as that of those who oppose our hypothesis (Bruins \& van der Plicht, Friedrich et al., all above). The enigma of the dating of the Santorini eruption is a long-lasting one, and because of its bearing on the dating of several eastern Mediterranean civilisations, has attracted significant attention. The potentially great importance of the Santorini olive branch used by Friedrich et al. (2006) was that it came from the site itself, and possibly belonged to the destruction layer. As such, the sincere and serious attempt to date it made by Friedrich et al. (2006) should be appreciated. Unfortunately, large olive branches may exist as dead limbs for a very long time and thus represent earlier periods.

We are dendrochronologists and tree biologists and we therefore focus our response on the tree-rings. Moreover, if the Santorini olive tree-ring data is not reliable there is therefore no in situ dating. All other indirect archaeological data emerging from sites outside Santorini, such as Crete and Egypt, and used for indirect dating of the Santorini eruption have their own inherited dating problems, as discussed by many others. We posit again that we consider the date of the Thera eruption based on the putative tree-ring sequence of a single olive tree (Friedrich et al. 2006) with great caution. As stated by Kuniholm (above), "[f] or successful radiocarbon wiggle-matching, if the radiocarbon laboratory is not given the precise ringcount between sampled sub-sections of the piece, any reported wiggle-match is immediately suspect. An approximation of the count just will not do. One or two or three or more missed (or missing) rings will skew the results by years or even decades", and so also will false or double rings, often found in Mediterranean trees (Cherubini et al. 2003, 2013).

The critical remarks by Bruins and van der Plicht and Friedrich et al. (above) indicate that publishing our original olive tree-ring findings (Cherubini et al. 2013) is of utmost importance. The fact that an evergreen Mediterranean tree species may form annual rings in one climatic area but not in another (e.g. Cherubini et al. 2003) is not always understood, and may cause confusion. Bruins and van der Plicht (above) didn't consider the flexible and very variable biology of cambial activity (and the resulting wood anatomy) in Mediterranean evergreens (e.g. Liphschitz \& Lev-Yadun 1986) and therefore cited papers that the first author of Cherubini et al. (above) published as a co-author (Rossi et al. 2013) or evaluated as the editor of the journal Dendrochronologia (Arnan et al. 2012) as contra evidence. However, the olive trees studied by Rossi et al. (2013) grew in a region with very low winter temperatures for cambial activity $\left(2-3^{\circ} \mathrm{C}\right)$, a temperature known to arrest cambial activity in Mediterranean evergreens (Liphschitz \& Lev-Yadun 1986 and citations therein).

\footnotetext{
${ }^{1}$ WSL Swiss Federal Institute for Forest, Snow and Landscape Research, CH-8903 Birmensdorf, Switzerland (Email:paolo.cherubini@wsl.ch; author for correspondence)

${ }^{2}$ Department of Biology \& Environment, Faculty of Natural Sciences, University of Haifa-Oranim, Tivon 36006, Israel (Email: levyadun@research.haifa.ac.il)

(C) Antiquity Publications Ltd.
} 
In Santorini, the low winter temperatures are around $10^{\circ} \mathrm{C}$, a much milder climate that allows for more flushes of growth and results in less pronounced seasonality (more false growth-rings). The study by Terral and Durand (2006) cited by Bruins and van der Plicht (above) does not prove anything concerning the possibility to determine whether olive growth-rings are indeed annual, but rather assumed that it is indeed so. As for Arnan et al. (2012: 11), they describe the problematic nature of olive tree-rings: "[t] ree-rings did not cross-date well, neither within nor between individuals", and only estimated the ages, a result that does not require safe identification of each and every growth-ring as needed for wiggle-match dating, the critical process in Friedrich et al. (2006).

The dendrochronological analysis of olive trees growing on Santorini (Cherubini et al. 2013) showed that the determination of their tree-ring number is impossible. Accordingly, caution should be taken with the dating by Friedrich et al. (2006) and their proposal cannot be used to discount a date range for the eruption of 1525-1490 BC as proposed by numerous other radiocarbon studies.

\section{References}

Arnan, X., B.C. Lopez, J. Martinez-Vilalta, M. ESTORACH \& R. POYATOS. 2012. The age of monumental olive trees (Olea europaea) in northeastern Spain. Dendrochronologia 30: 11-14. http://dx.doi.org/10.1016/j.dendro.2011.02.002

Cherubini, P., B.L. Gartner, R. Tognetti, O.U. BRÄKER, W. SCHOCH \& J.L. INNES. 2003. Identification, measurement and interpretation of tree rings in woody species from Mediterranean climates. Biological Reviews 78: 119-48. http://dx.doi.org/10.1017/S1464793102006000

Cherubini, P., T. Humbel, H. Beeckman, H. Gärtner, D. Mannes, C. Pearson, W. Schoch, R. TognetTi \& S. LeV-Yadun. 2013. Olive tree-ring problematic dating: a comparative analysis. PloS ONE 8: e54730. http://dx.doi.org/10.1371/journal.pone.0054730

Friedrich, W.L., B. Kromer, M. Friedrich, J. Heinemeier, T. Pfeiffer \& S. Talamo. 2006. Santorini eruption radiocarbon dated to 1627-1600 B.C. Science 312: 548. http://dx.doi.org/10.1126/science.1125087
Liphschitz, N. \& S. LeV-Yadun. 1986. Cambial activity of evergreen and seasonal dimorphics around the Mediterranean. IAWA Bulletin n.s. 7: 145-53.

Rossi, L., L. Sebastiani, R. Tognetti, R. D'Andria, G. Morelli \& P. Cherubini. 2013. Tree-ring wood anatomy and stable isotopes show structural and functional adjustments in olive trees under different water availability. Plant and Soil 372: 567-79. http://dx.doi.org/10.1007/s11104-013-1759-0

Terral, J.-F. \& A. Durand. 2006. Bio-archaeological evidence of olive tree (Olea europea L.) irrigation during the Middle Ages in southern France and north eastern Spain. Journal of Archaeological Science 33: 718-24. http://dx.doi.org/10.1016/j.jas.2005.10.004 